\title{
The impact of pre- and postnatal exposures on allergy related diseases in childhood: a controlled multicentre intervention study in primary health care
}

\author{
Christian Kvikne Dotterud*, Ola Storrø, Melanie Rae Simpson, Roar Johnsen and Torbjørn Øien
}

\begin{abstract}
Background: Environmental factors such as tobacco exposure, indoor climate and diet are known to be involved in the development of allergy related diseases. The aim was to determine the impact of altered exposure to these factors during pregnancy and infancy on the incidence of allergy related diseases at 2 years of age.

Methods: Children from a non-selected population of mothers were recruited to a controlled, multicenter intervention study in primary health care. The interventions were an increased maternal and infant intake of n-3 PUFAs and oily fish, reduced parental smoking, and reduced indoor dampness during pregnancy and the children's first 2 years of life. Questionnaires on baseline data and exposures, and health were collected at 2 years of age.

Results: The prevalence of smoking amongst the mothers and fathers was approximately halved at 2 years of age in the intervention cohort compared to the control cohort. The intake of n-3 PUFA supplement and oily fish among the children in the intervention cohort was increased. There was no significant change for indoor dampness. The odds ratio for the incidence of asthma was 0.72 (95\% Cl, 0.55-0.93; NNT $\mathrm{b} 53)$, and 0.75 for the use of asthma medication ( $95 \% \mathrm{Cl}, 0.58-0.96)$. The odds ratio for asthma among girls was 0.41 (95\% Cl 0.24-0.70; $\mathrm{NNT}_{\mathrm{b}} 32$ ), and for boys 0.93 (95\% Cl 0.68-1.26). There were no significant change for wheeze and atopic dermatitis.
\end{abstract}

Conclusion: Reduced tobacco exposure and increased intake of oily fish during pregnancy and early childhood may be effective in reducing the incidence of asthma at 2 years of age. The differential impact in boys and girls indicates that the pathophysiology of asthma may depend on the sex of the children.

Trial registration: Current Controlled Trials ISRCTN28090297.

Keywords: Asthma, Atopic, Dermatitis, Infant, Primary prevention, Public health

\section{Background}

The International Study of Asthma and Allergies in Childhood (ISAAC) has shown variations in the prevalence of allergy related diseases and that the worldwide time trend is increasing, particularly in developing countries $[1,2]$. Asher et al. suggested several factors to be involved, including lifestyle, dietary intake, microbial exposure, economic status, indoor and outdoor environment, climatic variation and awareness of disease [2]. The identification of which of these factors should be considered for

\footnotetext{
* Correspondence: christian.dotterud@gmail.com

Department of Public Health and General Practice, Norwegian University of Science and Technology (NTNU), N-7489 Trondheim, Norway
}

early intervention and their effectiveness in counteracting the increasing incidence of allergy related diseases depends on the results of controlled intervention studies [3].

The Prevention of Allergy among Children in Trondheim (PACT) study was established to evaluate the possibility of reducing the prevalence of allergy related diseases in children within the constraints of public funding and time expenditure in primary health care [4]. Participants, regardless of parental history of atopy were included, as a large proportion of allergy related diseases develop in "low risk" groups $[5,6]$, and "... a large number of people at small risk may give rise to more cases of disease than a small number who are at high risk" [7]. Smoking and environmental

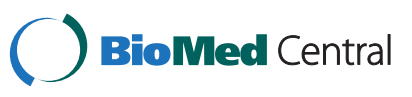


tobacco smoke (ETS) [8], oily fish, dietary n-3 polyunsaturated fatty acids (n-3 PUFAs) [9-11], and indoor dampness $[12,13]$, were associated with the development of allergy related diseases and were of particular scientific interested when this study commenced. We have previously reported a significant reduction in parental smoking and increased intake of oily fish and n-3 PUFAs in the intervention cohort compared to the control cohort [4]. We have also shown a risk reduction from eating oily fish once a week or more at 1 year of age in terms of parental reported atopic dermatitis (AD) at 2 years of age [14]. The impact of altered exposure to these factors through a population based intervention on the incidence of allergy related diseases is unknown $[15,16]$. It is generally accepted that there are sex differences in the incidence of asthma in children, and studies which clarify the sex related factors in the development of asthma are needed [16].

The aim of the PACT study was to examine the feasibility and effectiveness of a non-targeted population-based intervention to decrease parental smoking and indoor dampness and to increase intake of oily fish and n-3 PUFA. The impact of the intervention was evaluated in terms of the prevalence of parentally-reported allergy related diseases at 2 years of age.

\section{Methods}

\section{Design and participants}

The PACT-study is an on-going controlled, multicentre interventional study, described in detail elsewhere [4]. Here we present the results from when the children were 2 years of age. The study was conducted in Trondheim, a city in the central part of Norway with 165000 inhabitants and about 2100 births a year. The participants in both the control cohort and the intervention cohort followed the ordinary scheduled program for pre- and postnatal follow-up in primary health care.

The intervention cohort included women who presented to their GP or midwife for routine pregnancy check-ups after the implementation of the intervention in June 2002. Recruitment to the intervention cohort ended in May 2006. The control cohort recruitment commenced in September 2000 and consisted of pregnant women and children recruited at 6 weeks, 1 year and 2 years of age during routine check-ups with GPs and midwives across Trondheim. The recruitment of pregnant women to the control cohort ceased when recruitment into the intervention group commenced. When the first child in the intervention cohort was six weeks old, the recruitment of six-week-old children to the control cohort ceased, and analogously when they were 1 and 2 years of age. All women in the community who received an invitation to join the study, were willing and able to complete a questionnaire in Norwegian, and gave a written informed consent to participate were included. In this study, questionnaires on baseline data and all relevant exposures were collected during pregnancy and at 2 years of age. At the same time a questionnaire on the child's health were collected, which was adapted to the age group from the ISAAC questionnaire [17], and tested for reliability in a separate study [18]. The health questionnaire focused on allergy related diseases and use of medication.

The intervention program was implemented by the City Government as a part of recommended maternity care and life-style counselling throughout the city, regardless of participation in the PACT-study or not. The smoking cessation intervention was adapted from the United States Department of Health and Human Services Public Health Service (USHPS) guideline "Treating Tobacco Use and Dependence" [19]. The dietary intervention was advice of intake of oily fish twice a week and $1.2 \mathrm{~g}$ n-3 PUFA a day (5 ml cod liver oil) during pregnancy. After birth intake of n-3 PUFA to the child was recommended from 4-6 weeks and intake of oily fish at least twice a week from 6 months of age. In the indoor dampness intervention, advice on how to detect housing dampness damage and how to reduce exposure to indoor dampness were given.

Parental smoking was assessed at 2 years of age through two questions asking the women if they, or their partner, were smoking at start of pregnancy, and if they were smoking now. Information on consumption of $n-3$ PUFA, lean fish (cod and coalfish) and oily fish (redfish, halibut, salmon, trout, herring and mackerel) as dinner and sandwich spread were collected using validated semi quantitative food frequency questions with six categories, and re-categorized later in the analyses [20,21]. Housing conditions and indoor dampness were assessed through the reported presence of eight different indicators of indoor dampness, including mouldy or musty smell, moist cardboard and newspapers after storage, dew on windows, moist spots on ceilings, walls or wallpapers, leakage detection on water pipes or faucet, leakage from roof or ground, or moisture in the floors. Dampness index was defined by the sum of reported dampness indicators with a sum $\geq 3$ as the cutoff. In a separate study, information on education was collected from a sample of the control cohort and the intervention cohort by telephone interviews.

The primary outcome measure was based on a parental reported health questionnaire targeted to allergy related diseases. Allergic rhinoconjunctivitis (ARC) was not included as an outcome variable since incidence is low and an exact diagnosis of ARC is uncertain at 2 years of age. A child was considered to have asthma if the parents answered yes to "Has the child ever been diagnosed with asthma by a doctor?" Two questions in combination defined wheeze: "Has your child ever had whistling in the chest?" and "Has your child ever had episodes of wheezing 
or tightness in the chest?" Two questions in combination defined AD: "Has the child ever had eczema?" and "Has the child ever had an itchy rash which come and went over at least 6 months?" Parental atopy was defined as a history of asthma, ARC or AD in either the mother or father.

\section{Statistical analyses}

The presentation of the results and interpretations follow the TREND recommendations for public health intervention research [22]. STATA (version 12.1 IC) was used for all statistical analysis.

Logistic regression was used to estimate crude odds ratios for each of the exposure variables and outcome variables in the intervention cohort compared with the control cohort. To estimate adjusted odds ratios (aOR) we used multilevel logistic regression models with a random intercept for each maternal health care centre. This model accounted for possible clustering of participants within different centres. All demographic variables (except education and parental smoking), and infectious diseases and use of antibiotics were considered as possible confounding factors, and were tested in separate multilevel logistic models for alteration on the effect estimator. In the final model, adjustments were made for birth weight, maternal atopy, and RS-virus infection. To adjust for possible between-centre confounders we adjusted for the mean number of participants from the intervention cohort within each maternal health care centre.

In a sub-analysis, the differential impact of sex on the behavioural and outcome measures were tested with an interaction term between sex and cohort, and further stratified by sex to obtain separate ORs for boys and girls. In a sub-analysis, the differential impact of parental smoking (mother or father at 2 years of age) on the outcome measures were tested with an interaction term between parental smoking and cohort, and further stratified by parental smoking to obtain separate ORs for asthma among children with smoking and non-smoking parents. In the trend analysis, we used binary logistic regression to estimate p-values for trend in both cohorts. In the analysis of the differences between the participants at 2 years of age and drop-outs in the prenatal questionnaire on exposures was used. For all other data, the questionnaires on exposures and health from 2 years were used. Two-sided significance tests were used, with $\mathrm{p}<0.05$ considered statistically significant. For interaction terms, $\mathrm{p}<0.10$ were considered statistically significant.

\section{Ethical approval}

The study was approved by the Regional Committee for Medical Research Ethics for Central Norway (Ref. 120-2000). The Norwegian Data Inspectorate gave permission to process personal health data and one of the parents signed a written informed consent form (Ref 2003/953-3 KBE/-). The study is registered in Current Controlled Trials: ISRCTN28090297.

\section{Results \\ Participants}

Thirty-two of a total of 35 general practices, all seven community midwifes, and all 20 maternal health care centres recruited participants. The numbers of participants and time of inclusion are illustrated in Figure 1. The participants at 2 years of age in the intervention cohort and control cohort were comparable except from smoking status, single mothers and breastfeeding (Table 1).

In the intervention cohort, 2860 participants were included during pregnancy, and 1374 (48.0\%) of these could be followed prospectively until 2 years of age. When comparing these participants $(n=1374)$ to the drop-outs $(n=1486)$, the age of the mothers were 29.3 (SD 4.18) and 28.5 (SD 4.60), the number of maternal smokers at start pregnancy were $257(19.8 \%)$ and 345 (24.1\%), the numbers of paternal smokers at start pregnancy were $223(17.4 \%)$ and 335 (24.1\%), and 1116 (83.2\%) versus 1057 (70.7\%) were homeowners, respectively. There were no differences between the participants and drop-outs regarding education, parity, parental atopy, and pets.

In the control cohort, 1796 pregnant women were included during pregnancy, and $833(46.4 \%)$ of these could be followed prospectively until 2 years of age. When comparing these participants $(\mathrm{n}=833)$ to the drop-outs $(n=963)$, the age of the mothers were 29.2 (SD 4.61) and 28.2 (SD 4.75), the number of maternal smokers at start pregnancy were 204 (25.1\%) and 273 $(29.5 \%)$, the numbers of paternal smokers at start pregnancy were 171 (21.9\%) and 244 (27.7\%), and 660 (79.8\%) versus 652 (68.5\%) were homeowners, respectively. Again, there were no differences between the participants and drop-outs regarding education, parity, parental atopy, and pets. Additionally, 3947 participants who were recruited to the control cohort after birth completed the 2 years questionnaire, giving a total of 4780 participants at 2 years.

\section{Behavioural changes}

At 2 years of age, the prevalence of smoking amongst mothers $(\mathrm{OR}=0.46 ; \mathrm{p}<0.01$; Table 2$)$ and fathers $(\mathrm{OR}=0.57 ; \mathrm{p}<0.01)$ was almost halved in the intervention cohort compared to the control cohort. Intake of n-3 PUFA supplement was about 10 percentage points higher in the intervention cohort compared to the control cohort $(\mathrm{OR}=1.46 ; \mathrm{p}<0.01)$. The proportion having oily fish at least once a week was about 15 percentage points higher in the intervention cohort $(\mathrm{OR}=1.86 ; \mathrm{p}<0.01)$, and the intake of lean fish about 3 percentage points lower 


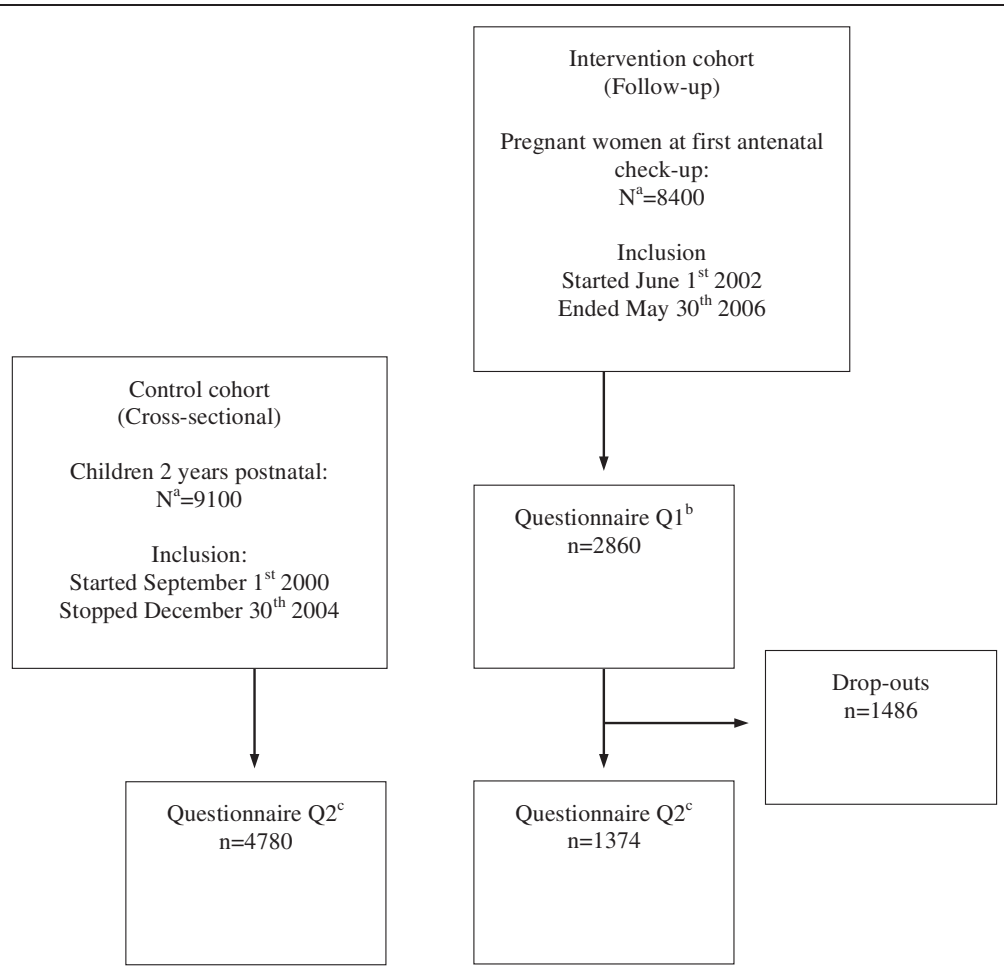

Figure 1 Flow of participants in the intervention cohort and control cohort. ${ }^{a}$ Total population of birth cohort in Trondheim during inclusion period. ${ }^{\mathrm{b}} \mathrm{Q} 1=$ Completed questionnaire on exposures at first antenatal check-up during pregnancy. ${ }^{c} \mathrm{Q} 2=$ Completed questionnaires on exposures and health at 2 years of age.

Table 1 Demographic characteristics of participants at 2 years of age

\begin{tabular}{|c|c|c|}
\hline \multirow[t]{2}{*}{ Characteristic } & Intervention cohort $\mathrm{N}=1374$ & \multirow{2}{*}{$\begin{array}{c}\text { Control cohort } N=4780 \\
\text { Mean (SD) }\end{array}$} \\
\hline & Mean (SD) & \\
\hline Age mother at delivery (years) & $29.8(4.21)$ & $29.3(4.68)$ \\
\hline Education ${ }^{a}$ mother (years) & $15.8(2.43)$ & $15.5(2.58)$ \\
\hline Education ${ }^{\mathrm{a}}$ father (years) & $15.1(2.77)$ & $15.0(2.97)$ \\
\hline \multirow[t]{2}{*}{ Birthweight (grams) } & $3601(545)$ & $3582(594)$ \\
\hline & n (\%) & n (\%) \\
\hline Boys & $667(49.3)$ & $2389(50.0)$ \\
\hline One or more sibling & $915(67.4)$ & $3265(69.3)$ \\
\hline Premature & $162(11.9)$ & $671(14.4)$ \\
\hline Single mother & $50(3.8)$ & $356(7.7)$ \\
\hline Breast fed $\geq 6$ months & $1053(76.9)$ & $3285(69.3)$ \\
\hline Smoking mother at start pregnancy & $186(13.8)$ & $862(18.6)$ \\
\hline Smoking father at start pregnancy & $205(15.7)$ & $917(21.3)$ \\
\hline Atopy $^{\mathrm{b}}$ mother & $652(47.8)$ & $1991(42.4)$ \\
\hline Atopy ${ }^{b}$ father & $578(42.3)$ & $1725(36.8)$ \\
\hline Atopy mother and father & $304(22.3)$ & $865(18.4)$ \\
\hline Dog in dwelling & $104(7.6)$ & $365(7.7)$ \\
\hline Cat in dwelling & $150(11.0)$ & $397(8.4)$ \\
\hline Homeowner & $1247(91.4)$ & $4118(87.4)$ \\
\hline
\end{tabular}

${ }^{a}$ Education data is based on a sample (Intervention cohort: $n=1062$. Control cohort: $n=1242$ ).

${ }^{\mathrm{b}}$ Defined as ever having had asthma, allergic rhinoconjunctivitis or AD. 
Table 2 Prevalence and odds ratios of exposures at 2 years of age

\begin{tabular}{|c|c|c|c|c|}
\hline & \multirow{2}{*}{$\begin{array}{l}\text { Intervention cohort } \mathrm{N}=1374 \\
\mathrm{n}(\%)\end{array}$} & \multirow{2}{*}{$\begin{array}{c}\text { Control cohort } N=4780 \\
n(\%)\end{array}$} & \multicolumn{2}{|c|}{ Odds ratio ${ }^{\mathrm{a}}(95 \% \mathrm{Cl})$} \\
\hline & & & Crude & Adjusted $^{\mathbf{b}}$ \\
\hline \multirow[t]{2}{*}{ Smoking mother at 2 years of age } & $132(9.8)$ & $879(19.0)$ & 0.46 & 0.47 \\
\hline & & & $(0.38-0.56)$ & $(0.39-0.58)$ \\
\hline \multirow[t]{2}{*}{ Smoking father at 2 years of age } & $143(11.2)$ & $751(17.9)$ & 0.57 & 0.56 \\
\hline & & & $(0.47-0.69)$ & $(0.46-0.68)$ \\
\hline \multirow[t]{2}{*}{ Indoor dampness index } & $53(3.9)$ & $179(3.8)$ & 1.02 & 1.09 \\
\hline & & & $(0.75-1.39)$ & $(0.79-1.51)$ \\
\hline \multirow[t]{2}{*}{$1.2 \mathrm{~g} \mathrm{n}-3$ PUFA four times a week or more } & $582(42.6)$ & 1591 (33.6) & 1.46 & 1.42 \\
\hline & & & $(1.29-1.66)$ & $(1.25-1.62)$ \\
\hline \multirow[t]{2}{*}{ Any kind of fish once a week or more } & $1011(73.6)$ & 3369 (70.6) & 1.16 & 1.13 \\
\hline & & & $(1.02-1.33)$ & $(0.98-1.30)$ \\
\hline \multirow[t]{2}{*}{ Oily fish once a week or more } & $687(50.0)$ & $1667(34.9)$ & 1.86 & 1.83 \\
\hline & & & $(1.65-2.11)$ & $(1.61-2.09)$ \\
\hline \multirow[t]{2}{*}{ Lean fish once a week or more } & $836(61.3)$ & $3062(64.6)$ & 0.87 & 0.85 \\
\hline & & & $(0.76-0.98)$ & $(0.74-0.97)$ \\
\hline
\end{tabular}

${ }^{\mathrm{a}}$ For intervention cohort versus control cohort.

${ }^{\mathrm{b}}$ Adjusted for birthweight, maternal atopy, RS-virus infection, maternal health care centre, and the proportion of participants from each cohort in each public health centre.

$(\mathrm{OR}=0.87 ; \mathrm{p}=0.02)$. Indoor dampness index $\geq 3$ was reported by approximately $4 \%$ of the participants in both cohorts $(\mathrm{OR}=1.02 ; \mathrm{p}=0.90)$.

\section{Incidence of allergic diseases}

The incidence of parentally reported doctor diagnosed asthma in the intervention cohort compared with the control cohort was reduced $(\mathrm{OR}=0.72 ; \mathrm{p}=0.01$; Table 3$)$. The absolute risk reduction (ARR) was $1.9 \%$ and numbers needed to treat to benefit $\left(\mathrm{NNT}_{\mathrm{b}}\right)$ was 53 . The risk of using asthma medication during the last 12 months was correspondingly lower in the intervention cohort
$(\mathrm{OR}=0.75 ; \mathrm{p}=0.02)$. The differences between the intervention and control cohorts with respect to the risk of wheeze $(\mathrm{OR}=0.92 ; \mathrm{p}=0.23)$ and $\mathrm{AD}(\mathrm{OR}=0.94 ; \mathrm{p}=0.47)$ were smaller and statistically non-significant.

Subgroup analysis stratified by sex disclosed a differential impact on asthma ( $\mathrm{p}$ for interaction $<0.01$ ) and the use of asthma medication ( $\mathrm{p}$ for interaction $=0.01$; Table 3 ). Among the boys, the impact on an asthma diagnosis was non-significant $(\mathrm{OR}=0.93 ; \mathrm{p}=0.63)$, and correspondingly non-significant on asthma medication $(\mathrm{OR}=0.95 ; \mathrm{p}=0.73)$. Among the girls, however, the impact on asthma $\left(\mathrm{OR}=0.41 ; \mathrm{p}<0.01 ; \mathrm{NNT}_{\mathbf{b}} 32\right)$ and the use of asthma

Table 3 Incidence and odds ratios of allergy related diseases among 2 years old children

\begin{tabular}{|c|c|c|c|c|c|c|c|c|c|c|}
\hline & \multicolumn{3}{|c|}{ Intervention cohort $\mathrm{N}=1374$} & \multicolumn{3}{|c|}{ Control cohort $N=4780$} & \multicolumn{4}{|c|}{ Odds ratio ${ }^{a}(95 \% \mathrm{Cl})$} \\
\hline & $\begin{array}{l}\text { Boys } \\
\text { n (\%) }\end{array}$ & $\begin{array}{l}\text { Girls } \\
\text { n (\%) }\end{array}$ & $\begin{array}{l}\text { Total } \\
\text { n (\%) }\end{array}$ & $\begin{array}{l}\text { Boys } \\
\text { n (\%) }\end{array}$ & $\begin{array}{l}\text { Girls } \\
\text { n (\%) }\end{array}$ & $\begin{array}{l}\text { Total } \\
\text { n (\%) }\end{array}$ & Boys crude & Girls crude & Total crude & Total adjusted $^{b}$ \\
\hline \multirow[t]{2}{*}{ Asthma } & 55 & 16 & 71 & 208 & 129 & 337 & 0.93 & 0.41 & 0.72 & 0.68 \\
\hline & $(8.1)$ & $(2.3)$ & $(5.2)$ & $(8.7)$ & $(5.4)$ & $(7.1)$ & $(0.68-1.26)$ & $(0.24-0.70)$ & $(0.55-0.93)$ & $(0.52-0.90)$ \\
\hline \multirow{2}{*}{$\begin{array}{l}\text { Used asthma medication } \\
\text { last } 12 \text { months }\end{array}$} & 60 & 19 & 79 & 222 & 138 & 360 & 0.95 & 0.46 & 0.75 & 0.69 \\
\hline & $(8.9)$ & $(2.7)$ & $(5.8)$ & $(9.3)$ & $(5.8)$ & $(7.5)$ & $(0.70-1.28)$ & $(0.28-0.74)$ & $(0.58-0.96)$ & $(0.53-0.91)$ \\
\hline \multirow[t]{2}{*}{ Wheeze } & 201 & 139 & 340 & 702 & 553 & 1255 & 1.02 & 0.82 & 0.92 & 0.91 \\
\hline & $(30.7)$ & $(20.4)$ & $(25.4)$ & $(30.3)$ & $(23.9)$ & $(27.1)$ & $(0.84-1.23)$ & $(0.66-1.00)$ & $(0.80-1.05)$ & $(0.79-1.06)$ \\
\hline \multirow[t]{2}{*}{$A D$} & 109 & 107 & 216 & 427 & 360 & 788 & 0.87 & 1.02 & 0.94 & 0.93 \\
\hline & $(16.5)$ & $(15.8)$ & $(16.1)$ & $(18.5)$ & $(15.5)$ & $(17.0)$ & $(0.69-1.10)$ & $(0.81-1.30)$ & $(0.80-1.11)$ & $(0.78-1.10)$ \\
\hline \multirow{2}{*}{$\begin{array}{l}\text { Ever used allergy } \\
\text { medication }\end{array}$} & 45 & 31 & 76 & 168 & 130 & 298 & 0.94 & 0.81 & 0.88 & 0.87 \\
\hline & $(6.7)$ & $(4.5)$ & $(5.6)$ & $(7.1)$ & $(5.5)$ & $(6.3)$ & $(0.67-1.32)$ & $(0.54-1.20)$ & $(0.68-1.14)$ & $(0.66-1.15)$ \\
\hline
\end{tabular}

${ }^{\mathrm{a}}$ For intervention cohort versus control cohort.

${ }^{\mathrm{b}}$ Adjusted for birthweight, maternal atopy, RS-virus infection, maternal health care centre, and the proportion of participants from each cohort in each public health centre. 
medication $(\mathrm{OR}=0.46 ; \mathrm{p}<0.01)$ was statistically significant. Subgroup analysis stratified by sex showed a borderline non-significant differential impact of the intervention on wheeze ( $\mathrm{p}$ for interaction 0.12). Among the boys, the impact on wheeze was non-significant $(\mathrm{OR}=1.02 ; \mathrm{p}=0.85)$. While it was borderline non-significant for girls $(\mathrm{OR}=0.82 ; \mathrm{p}=0.06)$, there was no differential impact of the intervention for $\mathrm{AD}$ in the subgroup analysis (p for interaction 0.34).

Subgroup analysis stratified on parental smoking at 2 years of age disclosed no differential impact of the intervention on asthma ( $p$ for interaction 0.71). The ORs for asthma in the intervention cohort compared with the control cohort among children with smoking parents $(\mathrm{OR}=0.80 ; \mathrm{p}=0.45)$ and non-smoking parents $(\mathrm{OR}=0.71 ; \mathrm{p}=0.02)$ were comparable.

\section{Other potential confounders}

Comparisons of reported infectious disease and use of antibiotics among the children at 2 years of age are presented in Table 4. There was an increased risk of intestinal infection $(\mathrm{p}<0.01)$, in the intervention cohort compared with the control cohort. There were no statistically significant differences between the intervention and control cohorts with respect to the risk of RS-virus infection, false croup, bronchitis, pneumonia, and the use of antibiotics. There were no statistically significant sex differences on infectious disease and use of antibiotics in either cohort (data not shown).

\section{Annual trend analysis}

No statistical significant annual trends were found with respect to asthma in either the intervention cohort $(\mathrm{OR}=0.92 ; \mathrm{p}=0.51)$ or the control cohort $(\mathrm{OR}=0.97$; $\mathrm{p}=0.52)$. No statistical significant annual trends were

Table 4 Distribution of potential confounders of reported infectious disease and use of antibiotics among 2 years old children

\begin{tabular}{lccc}
\hline & $\begin{array}{c}\text { Intervention cohort } \\
\mathbf{N}=\mathbf{1 3 7 4} \\
\mathbf{n ~ ( \% )}\end{array}$ & $\begin{array}{c}\text { Control cohort } \\
\mathbf{N}=\mathbf{4 7 8 0} \\
\mathbf{n}(\%)\end{array}$ & Odds ratio $^{\mathbf{a}}$ \\
& $75(5.5)$ & $209(4.4)$ & $\mathbf{( 9 5 \% ~ C l )}$ \\
\hline $\begin{array}{l}\text { Ever RS virus } \\
\text { infection }\end{array}$ & $373(27.2)$ & $864(18.1)$ & $1.68(1.46-1.94)$ \\
$\begin{array}{l}\text { Ever intestinal } \\
\text { infection }\end{array}$ & $188(13.7)$ & $675(14.2)$ & $0.96(0.81-1.14)$ \\
$\begin{array}{l}\text { Ever false croup } \\
\text { Ever bronchitis }\end{array}$ & $185(13.5)$ & $692(14.6)$ & $0.92(0.77-1.09)$ \\
$\begin{array}{l}\text { Ever pneumonia } \\
\text { Ever used }\end{array}$ & $87(6.4)$ & $345(7.3)$ & $0.87(0.68-1.11)$ \\
antibiotics & $601(44.0)$ & $2196(46.1)$ & $0.92(0.81-1.03)$ \\
\hline
\end{tabular}

${ }^{a}$ For intervention cohort versus control cohort.

${ }^{b}$ Ever used antibiotics for cold, inflammation of the ear, bronchitis, RS-virus infection, false croup, pneumonia, urinary infection and gut infection. found with respect to the use of asthma medicines in the intervention $(\mathrm{OR}=1.07 ; \mathrm{p}=0.58)$ and the control cohort $(\mathrm{OR}=1.04 ; \mathrm{p}=0.30)$.

\section{Discussion}

We found a significantly lower incidence in parentalreported doctor diagnosed asthma and use of asthma medication at 2 years of age in the intervention cohort compared to the control cohort. The reduced incidence for both asthma and the use of asthma medication was observed among girls. There was no significant difference in the incidence of $\mathrm{AD}$ and wheeze between the intervention and control cohorts, and similarly no difference was observed when the groups were stratified by sex.

The behavioural changes are described in details elsewhere $[4,23]$. Briefly, the participants in the intervention cohort smoked significantly less, had an increased intake of oily fish and n-3 PUFAs, but the same levels of indoor dampness compared to participants in the control cohort.

As we did not find any difference between the cohorts regarding indoor dampness, the reduced incidence of asthma could not be ascribed to this interventional measure. The study was not designed to identify the magnitude of effect of individual interventions, and it remains therefore uncertain if the observed reduction in asthma is solely due to the reduction in tobacco smoke exposure or dietary alterations or a combination of both. Prenatal and postnatal smoke exposure is generally considered to be a strong risk factor for the development of respiratory symptoms and asthma, particularly in early life $[24,25]$. The first national comprehensive mass media campaign on tobacco and health for many years in Norway was accomplished during the study period in 2003, and a total ban on smoking in restaurants and cafés first took effect on June 1st 2004. According to WHO' s European health for all database, the prevalence of regular daily smokers above 15 years of age in Norway has gradually declined during the study period, from $31.2 \%$ in year 2000 to $21 \%$ in 2008 [26]. In the subanalysis of this study, the impact of the intervention among children with smoking and non-smoking parents was comparable. This may indicate that the reduced incidence of asthma in the intervention cohort was not a consequence of reduced parental smoking per se. Rather, reduced smoking in Norway in general and smoking bans in public places could have contributed to less ETS exposure of the children in the intervention cohort independent of the smoking status of their parents. In randomised controlled trials dietary supplementation with n3-PUFAs does not seem effective in reducing the incidence of asthma as showed in a meta-analysis [27]. However, fish intake during pregnancy and during the first year of life has been found to be associated with a reduced risk of childhood asthma [28-30]. Summarised, 
the body of evidence of a preventive effect of reduced ETS exposure on childhood asthma is stronger than the evidence of a preventive effect of fish. As such, the reduced incidence of asthma and use of asthma medication in the intervention cohort may be attributed first and foremost to the reduced ETS exposure of the children and secondly to the increased intake of fish. The trend analysis showed no annual trends in either cohorts regarding asthma. This indicates that the reduced risk of asthma in the intervention cohort was not a consequence of an annual time trend.

We found no differences between the cohorts regarding $\mathrm{AD}$. We have previously reported a negative association between the intake of fish in childhood and $\mathrm{AD}$ at 2 years of age [14]. The increased fish consumption in the intervention cohort compared with the control cohort was likely too small to have an impact on AD on population level [4].

Our results demonstrated a strong differential impact on asthma and use of asthma medicines when stratified by sex. For wheeze, a similar differential impact was found, but was not statistically significant. An observational study has showed prenatal and postnatal exposure to tobacco smoke to be associated with asthma in 2 years old girls only [31], and cigarette smoking is associated with more respiratory symptoms among adolescent and adult women than among men [32,33]. A previous randomised intervention to reduce house dust mite, pet and food allergens, and passive smoking in a high-risk population of infants found an effect of the intervention on asthma-like symptoms in girls, but not on boys [34]. In line with this, our results indicate that the asthma phenotype among girls at 2 years of age is more susceptible to ETS and intake of oily fish than that of boys. The differential impact on boys and girls may indicate that the pathophysiology of asthma depends on the sex of the child.

The strengths of this study are the interventional, non-selected, population-based design with a large number of participants. The PACT study recruited participants from a primary health care population, regardless of parental history of atopy. The control cohort was established over a 2 year period immediately before the intervention was started, and from the same socio-economic areas. Participants in both cohorts followed the same scheduled program for pre- and postnatal follow-up in primary health care. Choosing a controlled design including whole birth cohorts made it possible to test the impact of the intervention program with a real life approach. A randomised control trial, with a co-existing cohort, would not be feasible in this type of broad population intervention, as both participants and health care workers move or communicate with each other introducing contamination of the control group. Secondly, comparing total birth cohorts also ensured high conformity between the cohorts regarding population size, race/ethnicity, maternal educational level, income, environment, urbanisation and social characteristics. The assessment of allergy related diseases were consistent through the observation period in both cohorts, and questions reporting factual information such as doctor diagnosed asthma were found reliable in a separate study [18].

Some $35 \%$ of the eligible pregnant women in Trondheim completed the questionnaires at 2 years of age. We had almost no active withdrawals in either cohort. The participation rate dropped during the study period [4], and could be a consequence of the long duration of the study resulting in a decreasing awareness, causing low recruitment activity among many GPs and midwifes, and not a consequence of self-selection among women. Decreased participation rate has been an increasing problem in epidemiological studies the recent years, but the participation rate experienced in this study might not introduce biased estimates if the participants are representative [35]. Results from the additional nonparticipants study $(\mathrm{n}=391)$, showed no significant differences between non-participants and participants in the PACT study [23]. This is reassuring and indicates that the PACT population is comparable to the general maternal population in Trondheim.

The drop-outs in in the intervention cohort were different from the participants at 2 years of age regarding maternal age, maternal smoking at start pregnancy and homeowner status, but the clinical differences were small. Due to the design of the study, only a portion of the control cohort was followed prospectively from pregnancy, however similar differences were seen between the drop-outs and participants in the intervention and control cohorts.

The participation rate varied between each maternal health care centre and they had a somewhat different proportion of participants from each cohort. Multilevel logistic regression models compensated for possible clustering on maternal health care centre. The proportion of participants from each cohort in each public health centre was added as a separate variable to the model to compensate for the different participant rates from each cohort in each maternal health centre. We were able to adjust for a large number of confounders, including RS virus infection and other potential clinical confounders. Summarised in the final adjusted model, the aOR of allergy related diseases was comparable with the crude analysis (Table 3). This indicated that the effect estimates were not biased. We were unable to adjust for education due to lack of parental educational data on all participants. Parental homeowner status was tested in the adjusted model as a proxy for socioeconomic status, but did not alter the effect estimates, and was excluded in the final adjusted model. 


\section{Conclusions}

Reduced environmental tobacco smoke and increased intake of oily fish during pregnancy and early childhood may be effective in reducing the incidence of asthma at 2 years of age in primary health care. The differential impact in boys and girls indicates that the pathophysiology of asthma is dependent on the sex of the child.

\section{Competing interests}

The authors declare that they have no competing interests.

\section{Authors' contributions}

$\mathrm{RJ}$ was responsible for the design, implementation of the trial, conduct, and contributed to analysis and interpretation and drafting the paper. $T \varnothing$ contributed to the design, implementation of the trial, validation and management of the main database, analysis and interpretation and drafting the paper. OS contributed to the design, implementation of the trial and drafting of the paper. CKD contributed to validation and management of the main database, was responsible for the analysis and interpretation, and was the principal author of the final report. MRS contributed to the interpretation of the analysis and drafting of the paper. All authors had full access to and can take responsibility for the data and analyses, and reviewed successive drafts of the paper. All authors read and approved the final manuscript.

\section{Acknowledgements}

We acknowledge all the pregnant women, mothers, fathers and their infants who repeatedly contributed to this trial. We also acknowledge all the nurses, midwives and GPs, and the local authorities in Trondheim for supporting and implementing the intervention in primary health care. We acknowledge Jon A Jensen, Marit Saunes, Guri Helmersen and Else Bartnes for their valuable contributions to this study, and Johan Håkon Bjørngaard for statistical advice.

This work was supported by The Norwegian Department of Health and Social affairs from 1997 to 2003; AstraZeneca Norge AS from 2000 to 2001; SINTEF Unimed in 1999; the Norwegian Research Council from 1999 to 2003; the Norwegian Medical Association; and the Norwegian University of Science and Technology. The founding sources had no role in the collection, analysis, and interpretation of data; in the writing of the report; and in the decision to submit the article for publication.

Received: 17 October 2012 Accepted: 29 January 2013

Published: 8 February 2013

\section{References}

1. Selnes A, Nystad W, Bolle R, Lund E: Diverging prevalence trends of atopic disorders in Norwegian children. Results from three cross-sectional studies. Allergy 2005, 60(7):894-899.

2. Asher MI, Montefort S, Bjorksten B, Lai CK, Strachan DP, Weiland SK, Williams $\mathrm{H}$ : Worldwide time trends in the prevalence of symptoms of asthma, allergic rhinoconjunctivitis, and eczema in childhood: ISAAC Phases One and Three repeat multicountry cross-sectional surveys. Lancet 2006, 368 (9537):733-743.

3. Wahn U, von Mutius E: Childhood risk factors for atopy and the importance of early intervention. J Allergy Clin Immunol 2001, 107(4):567-574.

4. Storro O, Oien T, Dotterud CK, Jenssen JA, Johnsen R: A primary healthcare intervention on pre- and postnatal risk factor behavior to prevent childhood allergy. The Prevention of Allergy among Children in Trondheim (PACT) study. BMC Public Health 2010, 10:443.

5. Bjerg A, Hedman L, Perzanowski MS, Platts-Mills T, Lundback B, Ronmark E: Family history of asthma and atopy: in-depth analyses of the impact on asthma and wheeze in 7- to 8-year-old children. Pediatrics 2007, 120(4):741-748.

6. Peroni DG, Piacentini GL, Bodini A, Rigotti E, Pigozzi R, Boner AL: Prevalence and risk factors for atopic dermatitis in preschool children. $\mathrm{Br} J$ Dermatol 2008, 158(3):539-543.

7. Rose G: Preventive strategy and general practice. Br J Gen Pract 1993, 43(369):138-139.
8. Nolte $H$, Backer V, Porsbjerg C: Environmental factors as a cause for the increase in allergic disease. Ann Allergy Asthma Immunol 2001, 87(6 Suppl 3):7-11.

9. Thien FCK, De Luca S, Woods RK, Abramson MJ: Dietary marine fatty acids (fish oil) for asthma in adults and children. Cochrane Database of Systematic Reviews 2000, (Issue 4):Art. No.: CD001283. doi:10.1002/14651858. CD001283.

10. Hirsch T, Kempe G: Consumption of omega-3 and omega- 6 fatty acids in former East and West Germany and changes in East Germany after the reunification. Respir Med 1999, 93(3):213-216.

11. Hodge L, Salome CM, Peat JK, Haby MM, Xuan W, Woolcock AJ: Consumption of oily fish and childhood asthma risk. The Medical journal of Australia 1996, 164(3):137-140.

12. Bornehag CG, Blomquist $G$, Gyntelberg F, Jarvholm B, Malmberg P, Nordvall $L$, Nielsen A, Pershagen G, Sundell J: Dampness in buildings and health. Nordic interdisciplinary review of the scientific evidence on associations between exposure to "dampness" in buildings and health effects (NORDDAMP). Indoor Air 2001, 11(2):72-86.

13. Dotterud LK, Van TD, Kvammen B, Dybendal T, Elsayed S, Falk ES: Allergen content in dust from homes and schools in northern Norway in relation to sensitization and allergy symptoms in schoolchildren. Clin Exp Allergy 1997, 27(3):252-261.

14. Oien T, Storro O, Johnsen R: Do early intake of fish and fish oil protect against eczema and doctor-diagnosed asthma at 2 years of age? A cohort study. J Epidemiol Community Health 2010, 64(2):124-129.

15. Halken S: Prevention of allergic disease in childhood: clinical and epidemiological aspects of primary and secondary allergy prevention. Pediatr Allergy Immunol 2004, 15(Suppl 16):4-5. 9-32.

16. Lux R, Awa W, Walter U: An interdisciplinary analysis of sex and gender in relation to the pathogenesis of bronchial asthma. Respir Med 2009, 103(5):637-649.

17. Johansson SG, Hourihane JO, Bousquet J, Bruijnzeel-Koomen C, Dreborg S, Haahtela T, Kowalski ML, Mygind N, Ring J, van Cauwenberge P, van HageHamsten $M$, Wuthrich $B$ : A revised nomenclature for allergy An EAACl position statement from the EAACI nomenclature task force. Allergy 2001, 56(9):813-824.

18. Oien T, Storro O, Johnsen R: Assessing atopic disease in children two to six years old: reliability of a revised questionnaire. Primary care respiratory journal: journal of the General Practice Airways Group 2008, 17(3):164-168.

19. Fiore MC: US public health service clinical practice guideline: treating tobacco use and dependence. Respir Care 2000, 45(10):1200-1262.

20. Jacobsen BK, Bonaa KH: The reproducibility of dietary data from a self-administered questionnaire. The Tromso Study. Int J Epidemiol 1990, 19(2):349-353.

21. Jacobsen BK, Knutsen SF, Knutsen R: The Tromso Heart Study: comparison of information from a short food frequency questionnaire with a dietary history survey. Scand J Soc Med 1987, 15(1):41-47.

22. Des Jarlais DC, Lyles C, Crepaz N: Improving the reporting quality of nonrandomized evaluations of behavioral and public health interventions: the TREND statement. Am J Public Health 2004, 94(3):361-366.

23. Øien T, Storrø O, Jenssen J, Johnsen R: The impact of a minimal smoking cessation intervention for pregnant women and their partners on perinatal smoking behaviour in primary health care: A real-life controlled study. BMC Public Health 2008, 8(1):325.

24. Bisgaard $\mathrm{H}$, Bonnelykke $\mathrm{K}$ : Long-term studies of the natural history of asthma in childhood. J Allergy Clin Immunol 2010, 126(2):187-197. quiz 198-189.

25. Baena-Cagnani CE, Gomez RM, Baena-Cagnani R, Canonica GW: Impact of environmental tobacco smoke and active tobacco smoking on the development and outcomes of asthma and rhinitis. Curr Opin Allergy Clin Immunol 2009, 9(2):136-140.

26. European health for all database (HFA-DB).: ; European health for all database (HFA-DB).

27. Anandan C, Nurmatov U, Sheikh A: Omega 3 and 6 oils for primary prevention of allergic disease: systematic review and meta-analysis. Allergy 2009, 64(6):840-848.

28. Kull I, Bergstrom A, Lilja G, Pershagen G, Wickman M: Fish consumption during the first year of life and development of allergic diseases during childhood. Allergy 2006, 61(8):1009-1015.

29. Goksor E, Alm B, Thengilsdottir H, Pettersson R, Aberg N, Wennergren G: Preschool wheeze - impact of early fish introduction and neonatal antibiotics. Acta Paediatr 2011, 100(12):1561-1566. 
30. Romieu I, Torrent M, Garcia-Esteban R, Ferrer C, Ribas-Fito N, Anto JM, Sunyer J: Maternal fish intake during pregnancy and atopy and asthma in infancy. Clin Exp Allergy 2007, 37(4):518-525.

31. Lodrup Carlsen KC, Lovik M, Granum B, Mowinckel P, Carlsen KH: Soluble CD14 at $2 \mathrm{yr}$ of age: gender-related effects of tobacco smoke exposure, recurrent infections and atopic diseases. Pediatr Allergy Immunol 2006, 17(4):304-312

32. Langhammer A, Johnsen R, Holmen J, Gulsvik A, Bjermer L: Cigarette smoking gives more respiratory symptoms among women than among men. The Nord-Trondelag Health Study (HUNT). J Epidemiol Community Health 2000, 54(12):917-922.

33. Holmen TL, Barrett-Connor E, Clausen J, Langhammer A, Holmen J, Bjermer $L:$ Gender differences in the impact of adolescent smoking on lung function and respiratory symptoms. the Nord-Trondelag Health Study, Norway, 1995-1997. Respir Med 2002, 96(10):796-804.

34. Schonberger HJ, Dompeling E, Knottnerus JA, Maas T, Muris JW, van Weel C, van Schayck CP: The PREVASC study: the clinical effect of a multifaceted educational intervention to prevent childhood asthma. Eur Respir J 2005, 25(4):660-670.

35. Galea S, Tracy M: Participation rates in epidemiologic studies. Ann Epidemiol 2007, 17(9):643-653.

doi:10.1186/1471-2458-13-123

Cite this article as: Dotterud et al:: The impact of pre- and postnatal exposures on allergy related diseases in childhood: a controlled multicentre intervention study in primary health care. BMC Public Health 2013 13:123.

\section{Submit your next manuscript to BioMed Central and take full advantage of:}

- Convenient online submission

- Thorough peer review

- No space constraints or color figure charges

- Immediate publication on acceptance

- Inclusion in PubMed, CAS, Scopus and Google Scholar

- Research which is freely available for redistribution 